Research Article

\title{
Investigation of Thermal Cooling Effectiveness of RRVCS for Permafrost Protection under Wide Expressway Embankment
}

\author{
Tao Tang $\left(\mathbb{D},{ }^{1}\right.$ Tao Ma $\mathbb{D},{ }^{1}$ Xiaoming Huang $\mathbb{D},{ }^{1}$ Qiuming Xiao $\mathbb{D}^{2},{ }^{2}$ Hao Wang, \\ and Guangji $\mathrm{Xu}^{1}$ \\ ${ }^{1}$ School of Transportation, Southeast University, Nanjing 210096, China \\ ${ }^{2}$ School of Traffic and Transportation Engineering, Changsha University of Science and Technology, Changsha 410004, China \\ ${ }^{3}$ Department of Civil and Environmental Engineering, Rutgers, The State University of New Jersey, Newark, NJ 08854, USA
}

Correspondence should be addressed to Tao Ma; matao@seu.edu.cn and Qiuming Xiao; xiaoxiaoyu69@sina.com

Received 4 March 2018; Accepted 28 May 2018; Published 19 July 2018

Academic Editor: Jinchang Wang

Copyright (c) 2018 Tao Tang et al. This is an open access article distributed under the Creative Commons Attribution License, which permits unrestricted use, distribution, and reproduction in any medium, provided the original work is properly cited.

In order to improve the thermal stability of wide embankment for the Qinghai-Tibet Expressway (QTE) to be constructed in permafrost zones on Qinghai-Tibet plateau, a new kind of reflective-resistant-ventilated coupling structure (RRVCS) was proposed and designed. A numerical model was then developed through ABAQUS to investigate the influences of RRVCS on the thermal regime of wide embankment. The temperature field and thawing depth of normal wide embankment without protective measures, wide embankment with crushed stone layer, and wide embankment with RRVCS were compared to verify the cooling effectiveness of RRVCS based on numerical analysis. Vermiculite powder has great influences on the thermal property of asphalt mixture, and it can be reduced by $22.8 \%, 29.5 \%, 37.3 \%$, and $50.6 \%$ after the addition of $4 \%, 6 \%, 8 \%$, and $10 \%$ vermiculite powder, respectively. Under the same condition, the temperature of RRVCS embankment is the lowest and its thermal stability is the best. Setting crushed stone layer can improve the thermal stability of embankment. However, the improvement is limited for wide embankment with width exceeding $26 \mathrm{~m}$. RRVCS has the best protective effects on the thermal stability of wide embankment and is recommended as a protective measure for wide embankment of expressway in permafrost regions of Qinghai-Tibet Plateau.

\section{Introduction}

As the first expressway connecting Tibet to other provinces in China, the Qinghai-Tibet Expressway (QTE) will be constructed on the Qinghai-Tibet Plateau in accordance with the China National Expressway Network Plan [1]. The construction of QTE is of great importance because it can eliminate traffic bottlenecks in Tibetan areas and promote China's social and economic development. However, it is quite difficult to build a high-quality expressway on the Qinghai-Tibet Plateau [2] due to its extreme conditions such as high altitude, low air temperature and pressure, and strong solar radiation [3]. Another difficulty is that the building of QTE, like the existing QinghaiTibet Highway (QTH), may have adverse effects on the fragile ecosystem of the Qinghai-Tibet Plateau [4]. More importantly, since QTE will pass through more than $500 \mathrm{~km}$ of continuous permafrost regions, a lot of technical barriers especially permafrost degradation have to be addressed [5].
Permafrost is very sensitive to climate change, and its strength decreases dramatically with rising temperature. Based on meteorological data available, it was predicted that air temperature over the Tibetan Plateau would increase $2.2^{\circ} \mathrm{C}$ to $2.6^{\circ} \mathrm{C}$ in the coming fifty years [6]. Because of climate warming and human activities, the permafrost in this area could thaw and lose its bearing capacity, leading to activelayer detachment failure, thaw subsidence, and failure of many other geohazards [7]. To address these issues, much effort has been exerted by researchers all over the world and a number of measures to cool down permafrost subgrade have been devised, including crushed stone embankment, thermosyphons, air-cooling ducts, awnings, insulating materials, raising the embankment height, and combinations of these methods [8-12]. While some are passive methods impeding the heat transferred to the frozen soil, others are proactive measures releasing the heat accumulated in permafrost embankment. Generally, all these methods are effective in 


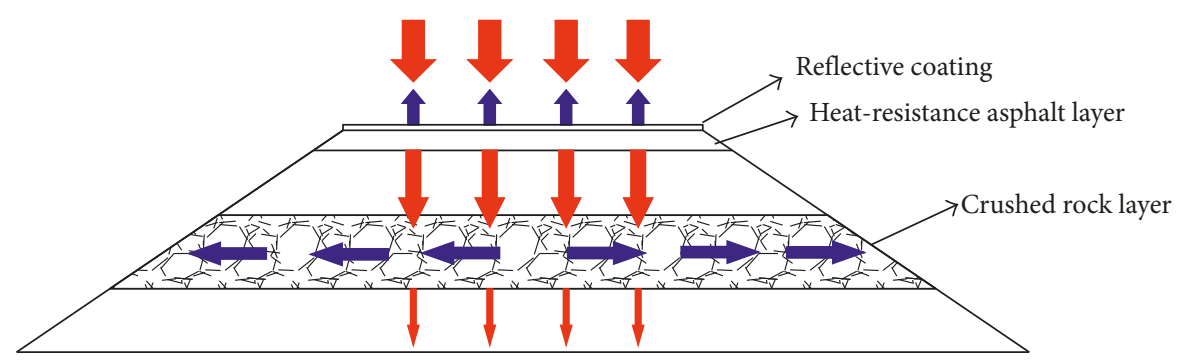

FIGURE 1: Schematic diagram of the reflective-resistant-ventilated coupling structure.

cooling current permafrost embankments according to engineering practices.

While most existing highways and railways in permafrost regions adopt narrow embankments whose widths are no more than $10 \mathrm{~m}$, QTE is characterized by wide embankment with width more than $24.5 \mathrm{~m}$, which is at least twice the width of current embankments. Due to the increased width of asphalt pavement, the heat-absorption intensity in wide embankment would be much higher compared with narrow embankment. Meanwhile, the heat at the embankment center is more difficult to dissipate outward due to the extended heat diffusion path, which can lead to faster permafrost degradation and more severe thaw settlement [12]. Therefore, striking differences exist between current narrow embankments and the new wide embankment of QTE. Since most of the existing cooling methods are based on narrow embankments, they may not be effective in cooling QTE's wide embankment.

Thus, this study aims to find effective cooling measurements for the wide embankment of QTE. To achieve this objective, a new kind of reflective-resistant-ventilated coupling structure (RRVCS) was proposed and designed. Based on the finite element software ABAQUS, a numerical model was built to simulate the temperature field of wide embankment and evaluate the effectiveness of RRVCS to improve the thermal stability of wide embankment. Another conventional cooling method, namely, crushed stone layer, was selected for comparison. The influences of different protective measures on the temperature field and thawing depth of underlying permafrost of wide embankment were investigated based on numerical analysis.

\section{Design of RRVCS}

To mitigate the thaw settlement of QTE and the degradation of its underlying permafrost, it is desired to explore strategies that make the pavement more heat resistant and the embankment more ventilated [13-15]. Among various possible strategies, pavements with high solar reflectance or low thermal conductivity might conduct less heat downward during heatabsorbing of summertime, while crushed stone embankment can cool permafrost by the air convective effect in the voids during heat-releasing of wintertime $[16,17]$. The combined strategies of reflective heat-resistant pavement and ventilated embankment could be a potential practice for improving the stability of the expressway embankment in the permafrost areas.

Therefore, a reflective-resistant-ventilated coupling structure (RRVCS) was proposed in this study. It consists of three

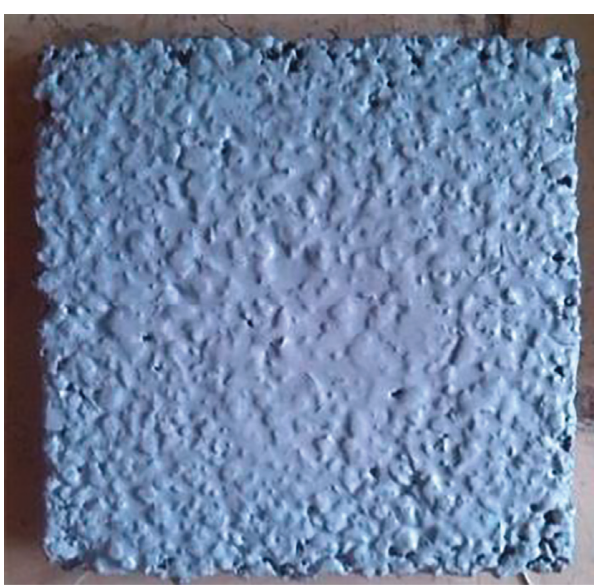

FIGURe 2: Photo of the reflective coating.

parts: reflective coating, heat-resistant pavement, and crushed stone embankment. The cooling effect of RRVCS includes the following: (1) the reflective coating would increase the albedo of road surface and decrease the solar radiation absorbed by asphalt pavement; (2) the heat-resistant pavement could impede the heat transferring downward, thus reducing the heat conducted to the frozen soil; and (3) the crushed stone embankment can dramatically release heat accumulated in permafrost embankment according to the Rayleigh-Bernard convection mechanism [18]. While (3) is embankment technology which embodies the function of ventilated, (1) and (2) are the pavement measures which manifest the action of reflective and resistant, respectively. Figure 1 is the schematic diagram of RRVCS. (The red arrows represent heat flowing inward, and the blue arrows represent heat flowing outward).

2.1. Reflective Coating. As the dark surface of asphalt pavement has strong heat absorption ability, it is considered to be one of the major causes for permafrost degradation. In order to prevent heat entering into asphalt pavement, a lot of heat reflective materials have been developed. Generally, their global solar reflectance is within the range of 0.4 to 0.8 [19]. In this paper, a white-colored thin layer was used as the reflective coating of RRVCS, as shown in Figure 2. Its solar reflectance was back calculated as 0.5 according to temperature test results. Considering the fact that the reflectivity of the coating can be reduced rapidly by traffic load and environment, its reflectivity was set to be 0.3 for numerical analysis to simulate the longterm behavior of the reflective coating. 


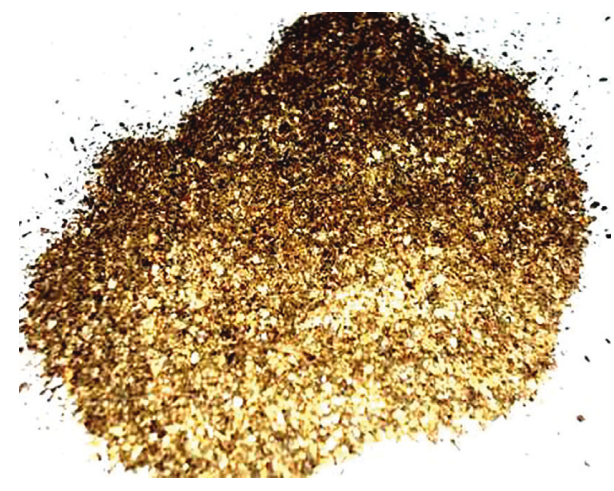

FIgUre 3: Photo of vermiculite powder.

2.2. Heat-Resistant Pavement. Vermiculite powder, as shown in Figure 3, is characterized as low thermal conductivity and excellent heat insulation. In this study, heat-resistant pavement was designed by adding vermiculite powder into asphalt mixture to lower its thermal conductivity. The maximum dosage was selected as $10 \%$ (by weight) of the aggregate to avoid its detrimental impacts on mixture's mechanical performances. Asphalt mixture of type AC-13 was designed, and its gradation is shown in Table 1. Here, SBS (styrenebutadiene-styrene) modified asphalt was used, and the asphalt content was $5.5 \%$. The coarse aggregate was basalt, and the mineral filler was made from limestone.

Asphalt mixtures with $0 \%, 4 \%, 6 \%, 8 \%$, and $10 \%$ of vermiculite were made according to China technical specification [20]. Thermal properties of the five types of asphalt mixtures, including heat capacity and thermal conductivity, were measured by a Mathis TCI thermal conductivity tester. The test results can be seen in Table 2 .

It can be observed that the thermal conductivity of asphalt mixtures decreases with vermiculite content increasing. Compared with the specimens without vermiculite, the thermal conductivity can be reduced by $22.8 \%, 29.5 \%, 37.3 \%$, and $50.6 \%$ after the addition of $4 \%, 6 \%, 8 \%$, and $10 \%$ vermiculite powder, respectively. The test results also indicate that a higher vermiculite content results in a lower specific heat capacity. For example, the specific heat capacity decreases $14.4 \%$ when vermiculite dosage increases from $0 \%$ to $10 \%$. In this study, asphalt mixture with $10 \%$ vermiculite was chosen as the heat-resistant pavement of RRVCS to prevent heat entering into the embankment as much as possible.
2.3. Crushed Stone Embankment. Crushed stone embankment is a common roadbed cooling method, which can lower the permafrost temperature based on the air convective effect in the crushed stone layer. It has been widely used in permafrost regions. It is proved that the cooling effects of crushed stone embankment are mainly influenced by the particle size and the thickness of the crushed stone layer [21]. Particles with diameters of $6 \sim 8 \mathrm{~cm}$ tend to have better cooling effect compared with others [22]. Although there exists an optimum thickness for the crushed stone layer, the thickness is too difficult to be determined because a lot of factors have to be considered. In this paper, a $1.5 \mathrm{~m}$ thick crushed stone layer with diameters of $6 \sim 8 \mathrm{~cm}$ was selected as the crushed stone embankment of RRVCS.

\section{Finite Element Modeling}

3.1. Fundamental Theory and Equations. The freezing and thawing of frozen soils are complex processes involving thermal transfer, moisture migration, deformation, and phase change. To simplify the numerical analysis, mass transfer and heat loss of vaporization were not considered in this study. Therefore, based on mass and energy conservation theory [23], two-dimensional heat-fluid coupling equations can be obtained as follows:

$$
\begin{aligned}
\left(c \rho_{\mathrm{S}}+\rho_{\mathrm{w}} \frac{\partial w_{\mathrm{u}}}{\partial T}\right) \frac{\partial T}{\partial t}= & \frac{\partial}{\partial x}\left[\left(k_{x}+L \rho_{\mathrm{w}} D_{x} \frac{\partial w_{\mathrm{u}}}{\partial T}\right) \frac{\partial T}{\partial x}\right] \\
& +\frac{\partial}{\partial y}\left[\left(k_{y}+L \rho_{\mathrm{w}} D_{y} \frac{\partial w_{\mathrm{u}}}{\partial T}\right) \frac{\partial T}{\partial y}\right]
\end{aligned}
$$

where $c$ is the soil specific heat capacity $\left(\mathrm{J} \cdot \mathrm{kg}^{-1} \cdot \mathrm{K}^{-1}\right), \rho_{\mathrm{S}}$ and $\rho_{\mathrm{w}}$ are the soil and water densities, respectively $\left(\mathrm{kg} \cdot \mathrm{m}^{-3}\right), w_{\mathrm{u}}$ is the volumetric unfrozen soil moisture $\left(\mathrm{m}^{3} \cdot \mathrm{m}^{-3}\right), T$ is the temperature $\left({ }^{\circ} \mathrm{C}\right), t$ is the time $(\mathrm{s}), k_{x}$ and $k_{y}$ are the thermal conductivity components of soils at $x$ and $y$ directions, respectively $\left(\mathrm{W} \cdot \mathrm{m}^{-1} \cdot \mathrm{K}^{-1}\right), D_{x}$ and $D_{y}$ are the water diffusivity components at $x$ and $y$ directions, respectively $\left(\mathrm{m}^{2} \cdot \mathrm{s}^{-1}\right), L$ is the volumetric latent heat of thawing $\left(\mathrm{J} \cdot \mathrm{m}^{-3}\right)$, and $x$ and $y$ are the horizontal and vertical directions, respectively.

Based on the physical state (frozen or thawed) of soils and the thermal properties of their components, the equivalent thermal parameters can be obtained as follows:

$$
\begin{gathered}
c \rho_{\mathrm{S}}+\rho_{\mathrm{w}} \frac{\partial w_{\mathrm{u}}}{\partial T}= \begin{cases}\left(c_{\mathrm{su}}+w_{0} c_{\mathrm{w}}\right) \rho_{\mathrm{d}}, & T \geq-\theta_{\mathrm{f}} \\
\rho_{\mathrm{d}} c_{\mathrm{sf}}+\rho_{\mathrm{d}} c_{\mathrm{i}} w_{0}+\rho_{\mathrm{d}}\left(c_{\mathrm{w}}-c_{\mathrm{i}}\right) \cdot w_{0} \theta_{\mathrm{f}}^{\mathrm{b}}(-T)^{-b}+L \cdot w_{0} \theta_{\mathrm{f}}^{\mathrm{b}} \cdot b \cdot(-T)^{-(\mathrm{b}+1)}, & T<-\theta_{\mathrm{f}},\end{cases} \\
k_{x}+L \rho_{\mathrm{w}} D_{x} \frac{\partial w_{\mathrm{u}}}{\partial T}=k_{y}+L \rho_{\mathrm{w}} D_{y} \frac{\partial w_{\mathrm{u}}}{\partial T}= \begin{cases}\lambda_{\mathrm{u}}, & T \geq-\theta_{\mathrm{f}} \\
\lambda_{\mathrm{f}}+\mathrm{LD} \cdot w_{0} \theta_{\mathrm{f}}^{\mathrm{b}} \cdot b(-T)^{-(\mathrm{b}+1)}, & T<-\theta_{\mathrm{f},}\end{cases}
\end{gathered}
$$

where $c_{\mathrm{sf}}$ and $c_{\mathrm{su}}$ are the specific heat capacities of soils at frozen and thawed states, respectively $\left(\mathrm{J} \cdot \mathrm{kg}^{-1} \cdot \mathrm{K}^{-1}\right), w_{0}$ is the volumetric unfrozen water content at the initial state $\left(\mathrm{m}^{3} \cdot \mathrm{m}^{-3}\right), c_{\mathrm{i}}$ is the specific heat capacity of ice $\left(\mathrm{J} \cdot \mathrm{kg}^{-1} \cdot \mathrm{K}^{-1}\right)$, 
Table 1: Aggregate gradation for AC-13 mixture.

\begin{tabular}{lcccccccccc}
\hline Sieve sizes (mm) & 16.0 & 13.2 & 9.5 & 4.75 & 2.36 & 1.18 & 0.6 & 0.3 & 0.15 & 0.075 \\
\hline Passing (\%) & 100 & 96.6 & 70.1 & 43.2 & 32.5 & 23.7 & 17.2 & 12.0 & 8.5 & 6.8 \\
\hline
\end{tabular}

TABLE 2: Test results of the thermal parameters of asphalt mixture.

\begin{tabular}{lccccc}
\hline Vermiculite dosage $(\%)$ & 0 & 4 & 6 & 8 & 10 \\
\hline Thermal conductivity $(\mathrm{W} / \mathrm{m} \cdot \mathrm{K})$ & 1.154 & 0.891 & 0.814 & 0.724 & 0.57 \\
Specific heat capacity $(\mathrm{J} / \mathrm{kg} \cdot \mathrm{K})$ & 716.24 & 691.68 & 657.44 & 633.62 & 613.24 \\
\hline
\end{tabular}

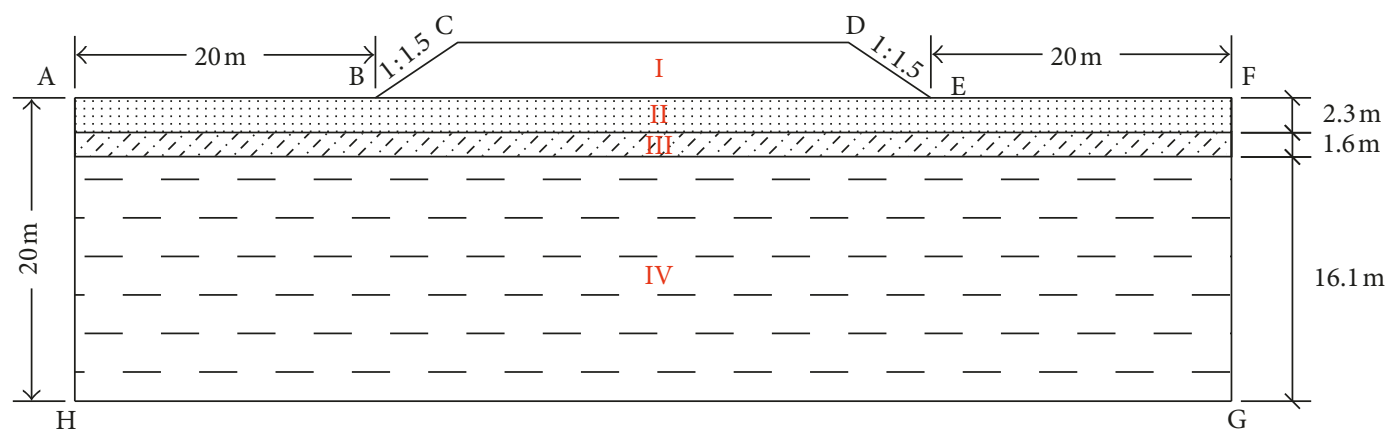

FIGURE 4: Geometric sketch of computational region.

$c_{\mathrm{w}}$ is the specific heat capacity of water $\left(\mathrm{J} \cdot \mathrm{kg}^{-1} \cdot \mathrm{K}^{-1}\right), \rho_{\mathrm{d}}$ is the soil dry density $\left(\mathrm{kg} \cdot \mathrm{m}^{-3}\right), \theta_{\mathrm{f}}$ is the absolute freezing temperature, $b$ is a constant related to soil type, $\lambda_{\mathrm{f}}$ and $\lambda_{\mathrm{u}}$ are the soil thermal conductivities in the frozen and thawed states, respectively $\left(\mathrm{W} \cdot \mathrm{m}^{-1} \cdot \mathrm{K}^{-1}\right)$, and $D$ is the water diffusivity of soils $\left(\mathrm{m}^{2} \cdot \mathrm{s}^{-1}\right)$.

The crushed stone layer in highway embankment is a porous media, in which the heat convects unsteadily. Therefore, it is different from the other layers of the embankment. The governing equations for mass, momentum, and energy of the crushed stone layer are given as follows [24]:

Continuity:

$$
\frac{\partial \rho}{\partial t}+\frac{\partial(\rho u)}{\partial t}+\frac{\partial(\rho v)}{\partial t}
$$

Momentum:

$$
\begin{aligned}
& u=-\frac{K}{\mu} \frac{\partial \rho}{\partial x} \\
& v=-\frac{K}{\mu}\left\{\frac{\partial \rho}{\partial x}-\rho_{0}\left[1-\beta\left(T-T_{0}\right) g\right]\right\} .
\end{aligned}
$$

Energy:

$$
C_{\mathrm{e}} \frac{\partial T}{\partial t}+C_{\mathrm{a}}\left(u \frac{\partial T}{\partial x}+v \frac{\partial T}{\partial y}\right)=\frac{\partial}{\partial y}\left(k_{y} \frac{\partial T}{\partial y}\right)+\frac{\partial}{\partial x}\left(k_{x} \frac{\partial T}{\partial x}\right)
$$

where $\rho$ is the density of air in porous medium, which can be decided by air temperature $\left(\rho=\rho_{0}\left[1-\beta\left(T-T_{0}\right)\right]\right)$; $\rho_{0}$ and $T_{0}$ are the reference air density and temperature, respectively; $\beta$ is the air thermal expansion coefficient; $u$ and $v$ are the components of air velocities; $K$ is the permeability of porous medium; $\mu$ is the dynamic air viscosity; $p$ is the air pressure; $C_{a}$ is the air specific heat at constant pressure; and $C_{\mathrm{e}}$ is the effective volumetric heat capacity.

3.2. Numerical Model and Parameters. Figure 4 shows the geometric sketch of computational region for the numerical model. Part I represents the wide embankment which is $50 \mathrm{~m}$ in width, $3 \mathrm{~m}$ in height, and 1:1.5 for the side slope gradient. According to the monitoring section $\mathrm{K} 3+016$ of QinghaiTibet Highway, the natural ground consists of three layers represented by Parts II, III, and IV, respectively. To eliminate the influence of model size on the simulation results, the natural ground depth underlying embankment is chosen as $20 \mathrm{~m}$ while the flank fields are extended for $20 \mathrm{~m}$ from both slope toes of embankment. The specific material parameters for different soils are seen in Table 3. The pavement structure and corresponding material parameters are listed in Table 4. To analyze the influences of embankment width on the cooling effectiveness of different measures, the width of embankment in the numerical model is adjustable. DC2D8 (eight-node quadrilateral heat-transmitting element) was adopted in the numerical model. And user-defined subordinate program named as "UMATHT" was developed to calculate the equivalent thermal parameters of soils. During numerical modeling, the $1.5 \mathrm{~m}$ thick crushed stone layer was set at $0.5 \mathrm{~m}$ above the surface of the natural ground. Table 5 lists the thermal parameters of crushed stone layer. 
TABLE 3: Material parameters for different soils.

\begin{tabular}{lcccc}
\hline Material parameters & $\begin{array}{c}\text { Part I } \\
\text { Gravel soil }\end{array}$ & $\begin{array}{c}\text { Part II } \\
\text { Pebbly clay }\end{array}$ & $\begin{array}{c}\text { Part III } \\
\text { Gravel loam }\end{array}$ & $\begin{array}{c}\text { Part IV } \\
\text { Strong erosion mudstone }\end{array}$ \\
\hline$W_{0}(\%)$ & 25 & 30 & 30 & 30 \\
$\rho_{\mathrm{d}}\left(\mathrm{kg} \cdot \mathrm{m}^{-3}\right)$ & 1800 & 1700 & 1300 & 1500 \\
$c_{\mathrm{sf}}\left(\mathrm{kJ} \cdot \mathrm{kg}^{-1} \cdot \mathrm{K}^{-1}\right)$ & 0.71 & 0.73 & 0.75 & 0.75 \\
$c_{\mathrm{su}}\left(\mathrm{kJ} \cdot \mathrm{kg}^{-1} \cdot \mathrm{K}^{-1}\right)$ & 0.79 & 0.84 & 0.84 & 0.84 \\
$c_{\mathrm{i}}\left(\mathrm{kJ} \cdot \mathrm{kg}^{-1} \cdot \mathrm{K}^{-1}\right)$ & 2.09 & 2.09 & 2.09 & 2.09 \\
$c_{\mathrm{w}}\left(\mathrm{kJ} \cdot \mathrm{kg}^{-1} \cdot \mathrm{K}^{-1}\right)$ & 4.182 & 4.182 & 4.182 & 4.182 \\
$\lambda_{\mathrm{f}}\left(\mathrm{W} \cdot \mathrm{m}^{-1} \cdot \mathrm{K}^{-1}\right)$ & 1.980 & 2.69 & 1.22 & 1.82 \\
$\lambda_{\mathrm{u}}\left(\mathrm{W} \cdot \mathrm{m}^{-1} \cdot \mathrm{K}^{-1}\right)$ & 1.919 & 1.95 & 0.87 & 1.47 \\
$-\theta_{\mathrm{f}}\left({ }^{\circ} \mathrm{C}\right)$ & -0.20 & -0.10 & -0.19 & -0.05 \\
$D\left(\mathrm{~m}^{2} \cdot \mathrm{s}^{-1}\right)$ & $9.35 \times 10^{-6}$ & 4.66 & 3.73 & 3.44 \\
$B$ & 0.610 & 0.733 & 0.574 & 0.474 \\
$L\left(\mathrm{~J} \cdot \mathrm{m}^{-3}\right)$ & 334.56 & 334.56 & 334.56 & 334.56 \\
\hline
\end{tabular}

TABLE 4: Pavement structure and material parameters.

\begin{tabular}{lccccc}
\hline & Upper asphalt layer & Lower asphalt layer & Base & Subbase & Cushion \\
\hline Material & AC13 & AC20 & ATP25 & Cement stabilized macadam & Graded gravel \\
Thickness $(\mathrm{m})$ & 0.04 & 0.05 & 0.12 & 0.24 & 0.2 \\
Density $\left(\mathrm{kg} \cdot \mathrm{m}^{-3}\right)$ & 2300 & 2320 & 2350 & 2200 & 2000 \\
Specific capacity $\left(\mathrm{J} \cdot \mathrm{kg}^{-1} \cdot \mathrm{K}^{-1}\right)$ & 1670 & 1670 & 1260 & 960 & 1100 \\
Thermal conductivity $\left(\mathrm{W} \cdot \mathrm{m}^{-1} \cdot \mathrm{K}^{-1}\right)$ & 1.15 & 1.20 & 0.81 & 1.56 & 1.68 \\
\hline
\end{tabular}

TABLE 5: Thermal parameters for crushed stone layer.

\begin{tabular}{|c|c|c|c|}
\hline Materials & Density $\left(\mathrm{kg} \cdot \mathrm{m}^{-3}\right)$ & Specific capacity $\left(\mathrm{J} \cdot \mathrm{kg}^{-1} \cdot \mathrm{K}^{-1}\right)$ & Thermal conductivity $\left(\mathrm{W} \cdot \mathrm{m}^{-1} \cdot \mathrm{K}^{-1}\right)$ \\
\hline Crushed stone & 1490 & 839 & 0.40 \\
\hline
\end{tabular}

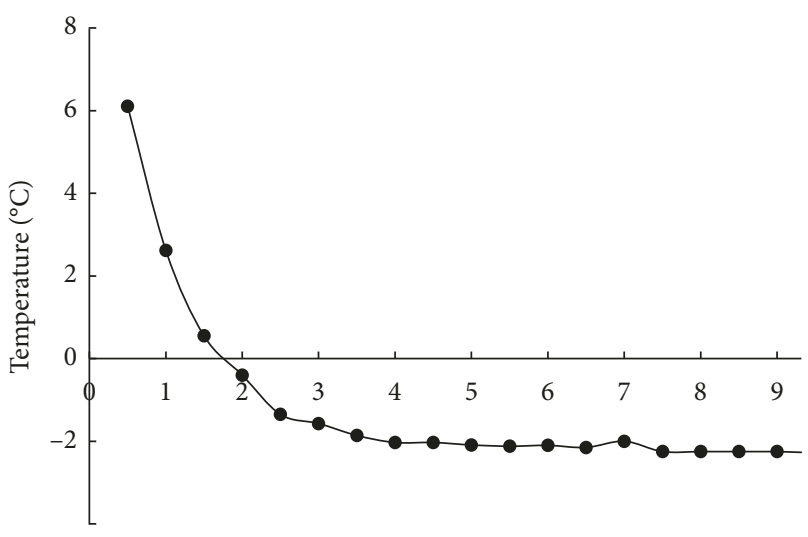

FIgURE 5: Initial ground temperature at different depths.

3.3. Initial and Boundary Conditions. The temperature field data at section K3 + 016 of QTH in August 2000 were used in this study as the initial ground temperatures of the model. Figure 5 shows the initial temperature at different depths from the natural ground surface (represented by line AF in Figure 4).

Most of the current temperature field models of permafrost embankments used the first thermal boundary condition. However, this kind of boundary condition is based on observed temperature data of narrow embankments and

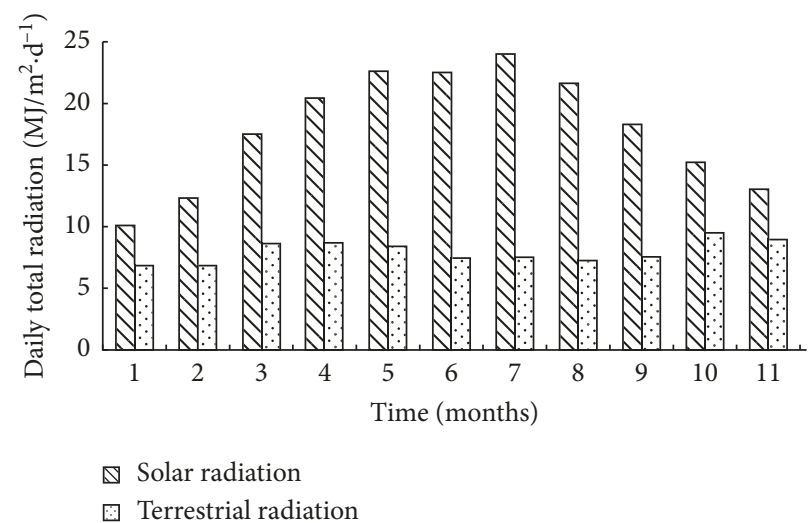

Figure 6: Field observed data for solar and ground radiation.

cannot be simply applied to wide embankments. Therefore, in this study, the second and third thermal boundary conditions including solar radiation, terrestrial radiation, wind velocity, and air temperature were adopted in the model. The field observed data for solar and terrestrial radiation which are used in numerical analysis are given in Figure 6. The monthly average wind velocities are summarized in Table 6 .

According to previous research [25], the air temperature increment after fifty years was predicted to be $2.6^{\circ} \mathrm{C}$. During numerical analysis, the monthly average air temperature was 
TABLE 6: Monthly average wind velocities.

\begin{tabular}{|c|c|c|c|c|c|c|c|c|c|c|c|c|}
\hline Month & 1 & 2 & 3 & 4 & 5 & 6 & 7 & 8 & 9 & 10 & 11 & 12 \\
\hline Wind velocities $\left(\mathrm{m} \cdot \mathrm{s}^{-1}\right)$ & 5.69 & 5.83 & 5.92 & 4.79 & 4.37 & 4.11 & 3.72 & 3.37 & 3.38 & 3.58 & 4.29 & 5.23 \\
\hline
\end{tabular}

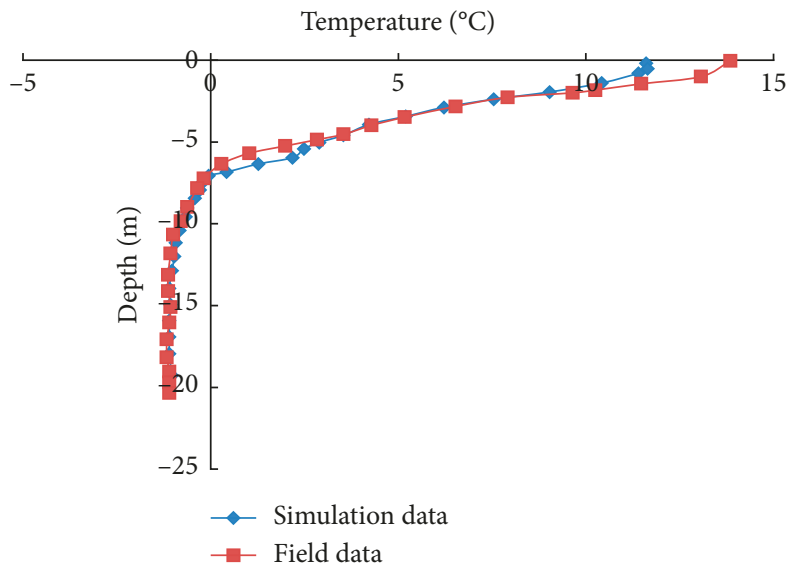

FIGURE 7: Comparison between calculated and measured temperature data in September.

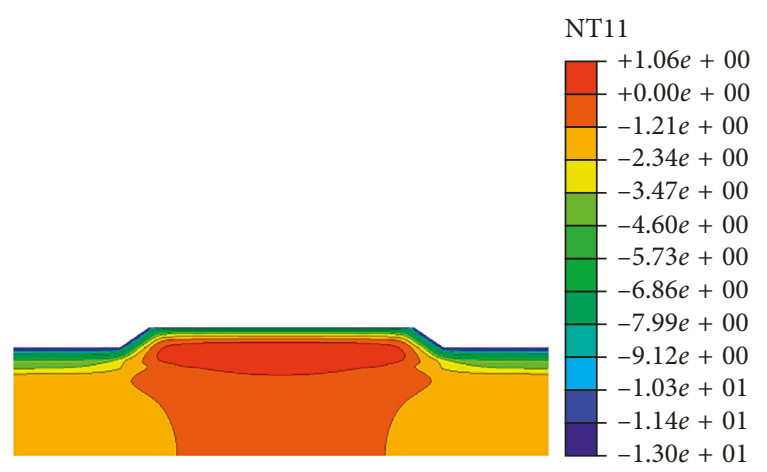

(a)

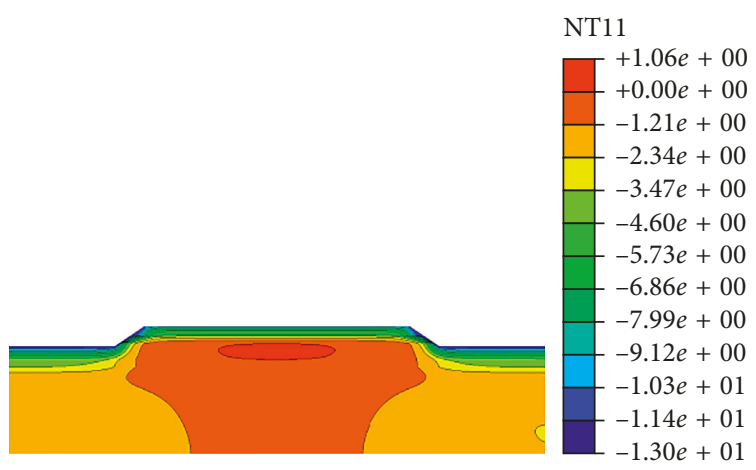

(b)

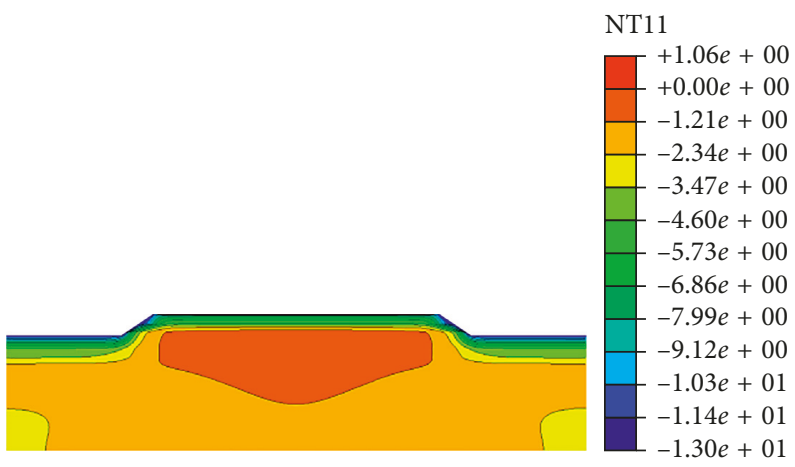

(c)

FIGURE 8: The tenth-year temperature fields in January for different embankments: (a) normal embankment, (b) CS embankment, and (c) RRVCS embankment.

described by sine function, as shown in (6). User-defined subordinate programs DFLUX and FILM were developed to define the second thermal boundary condition (solar radiation and terrestrial radiation) and the third thermal boundary condition (wind velocity and air temperature), respectively: 


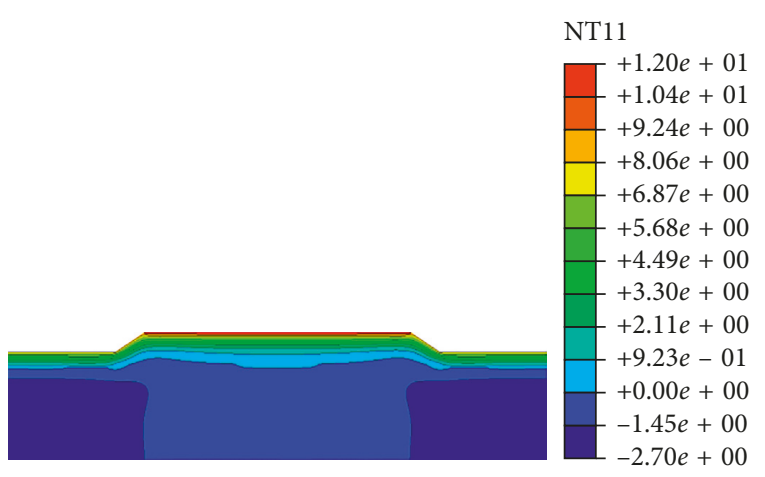

(a)

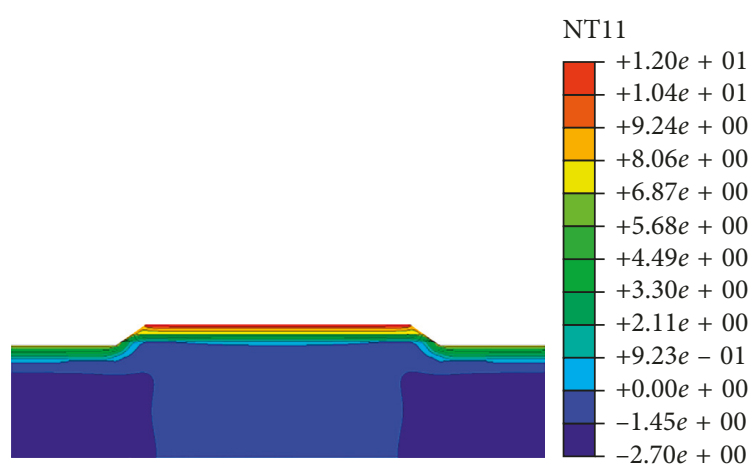

(b)

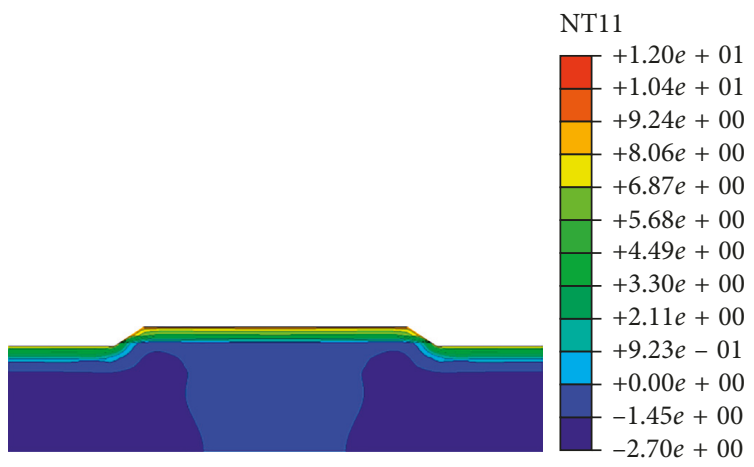

(c)

FiguRE 9: The tenth-year temperature fields in August for different embankments: (a) normal embankment, (b) CS embankment, (c) and RRVCS embankment.

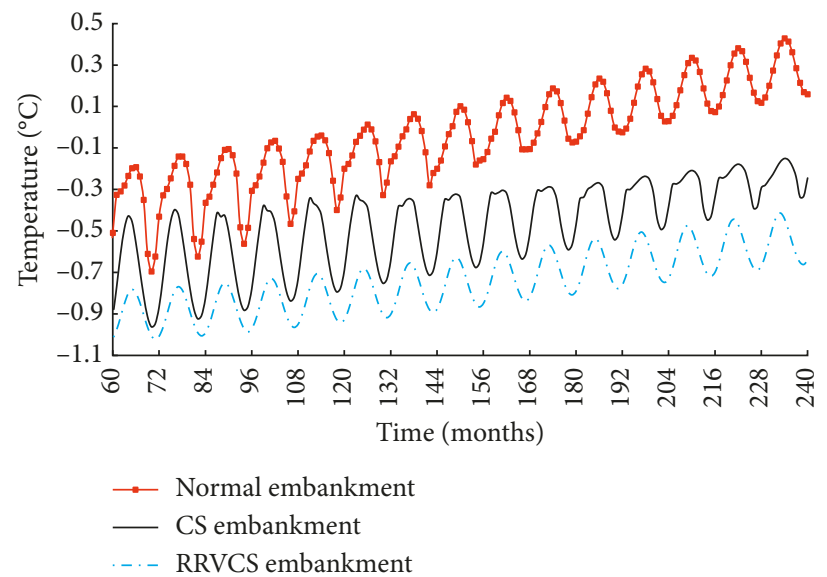

FIgURE 10: Temperature variations with service time for different embankments.

$$
T=-5.2+11.3 \sin \left(\frac{2 \pi}{12} t+\frac{5 \pi}{9}\right)+\frac{2.6 t}{600}
$$

where $T$ is the monthly average air temperature $\left({ }^{\circ} \mathrm{C}\right)$ and $t$ is the time (month).

3.4. Verification of Numerical Analysis. To verify the validity of finite element modeling, the temperature field of section $\mathrm{K} 3+016$ of the Qinghai-Tibet Highway was calculated using the numerical model. Figure 7 shows the field temperature data and the simulation data at different depths in September (along the embankment centerline). During numerical analysis, the calculation parameters are fixed and boundary conditions are simplified. Therefore, the simulation data and field data are not exactly the same. However, they are close to each other and present similar variation trend, which proves the feasibility of the numerical model. 


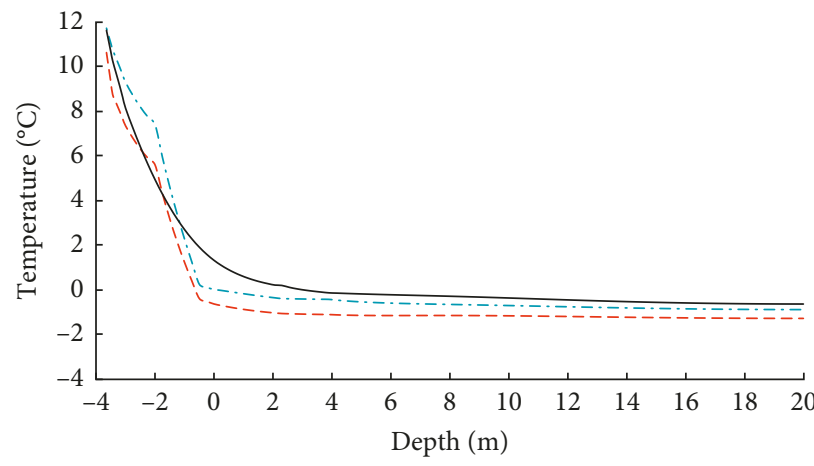

- - RRVCS embankment

- Normal embankment

-..- CS embankment

Figure 11: Temperature variations with depth at centerline of embankments.
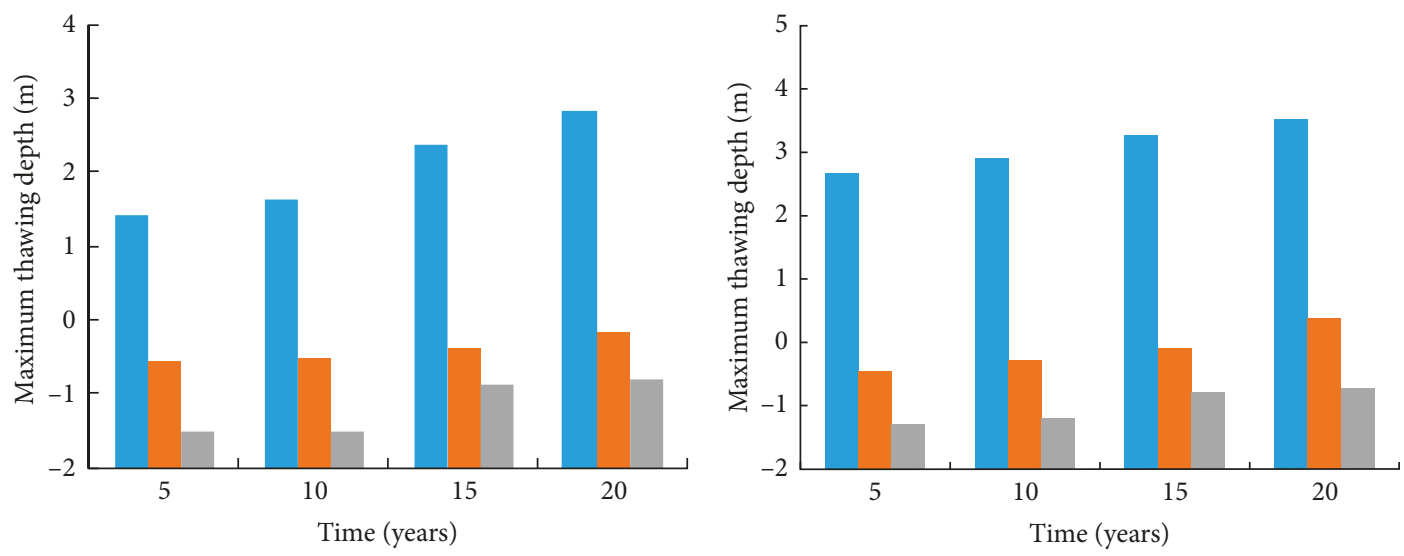

- Normal embankment

- CS embankment

- Normal embankment

- CS embankment

- RRVCS embankment

nRVCS embankment

(a)

(b)
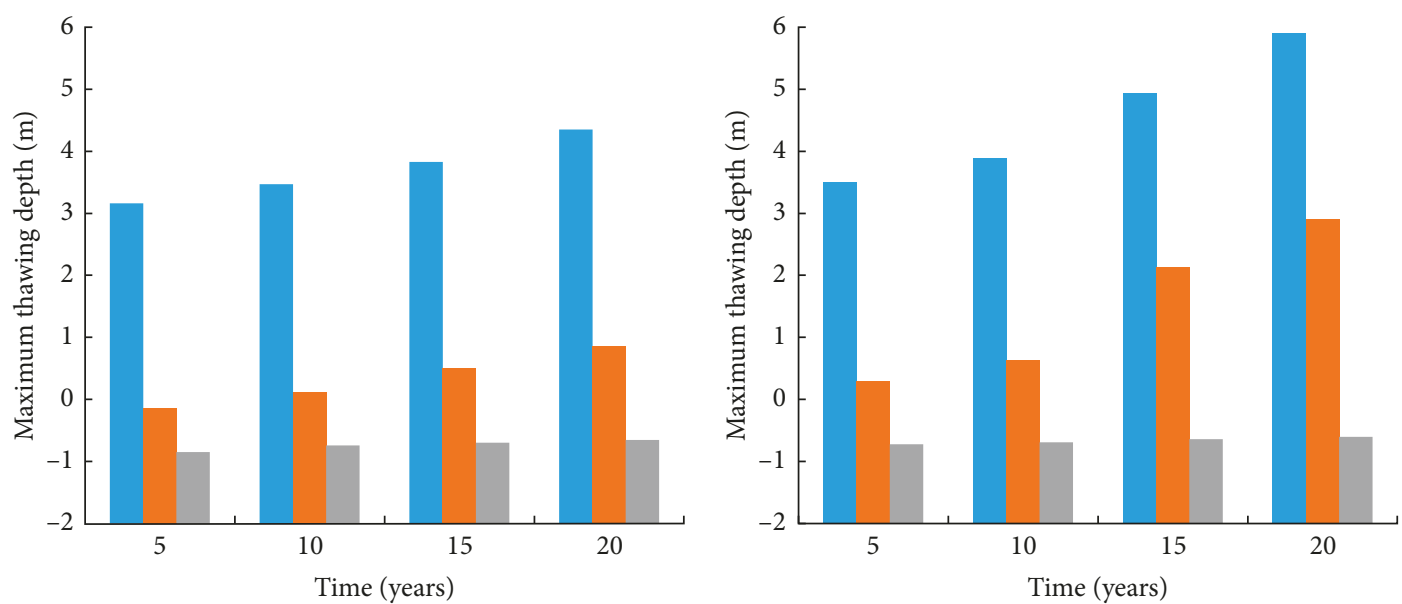

- Normal embankment

- CS embankment

- Normal embankment

- CS embankment

- RRVCS embankment

(c)

(d)

Figure 12: Continued. 


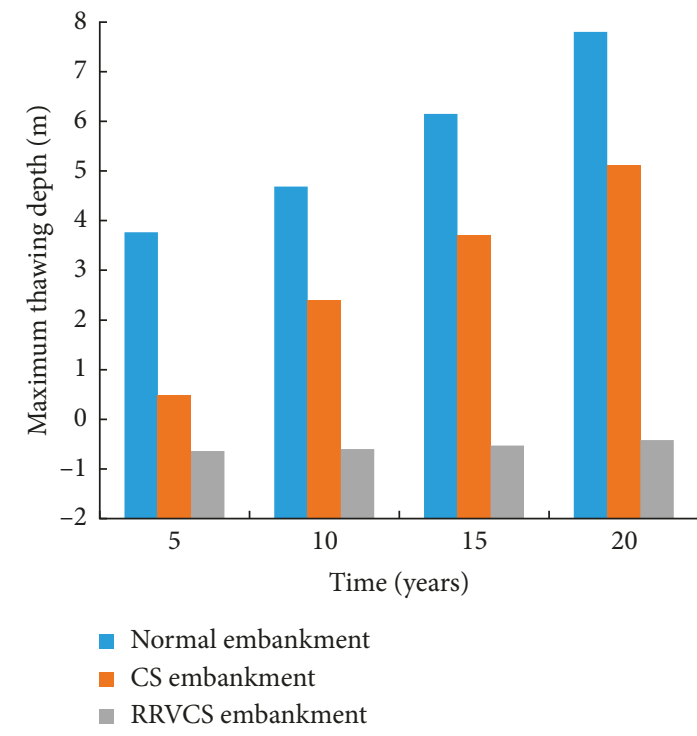

(e)

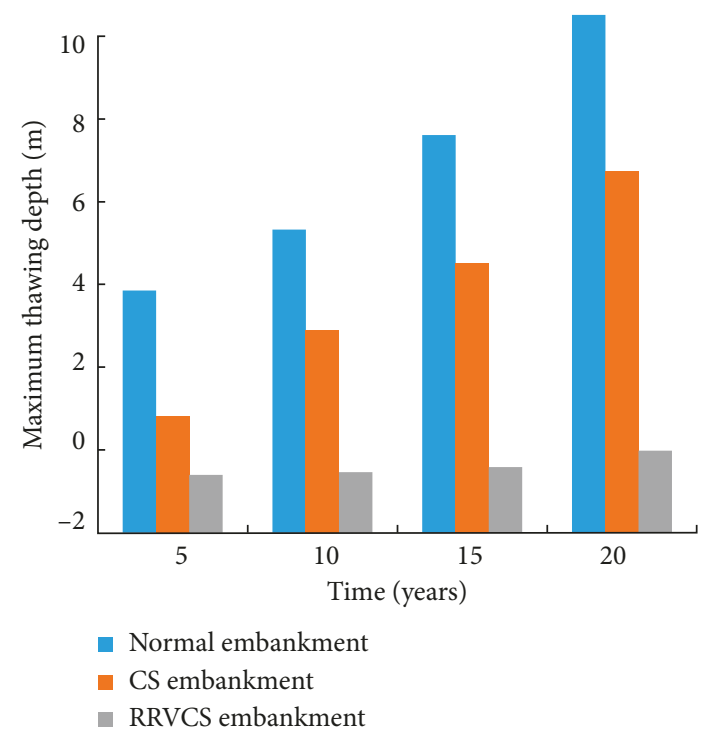

(f)

FIGURE 12: The maximum thawing depth versus service time for embankments with different widths: (a) $10 \mathrm{~m}$, (b) $18 \mathrm{~m}$, (c) $26 \mathrm{~m}$, (d) $34 \mathrm{~m}$, (e) $42 \mathrm{~m}$, and (f) $50 \mathrm{~m}$.

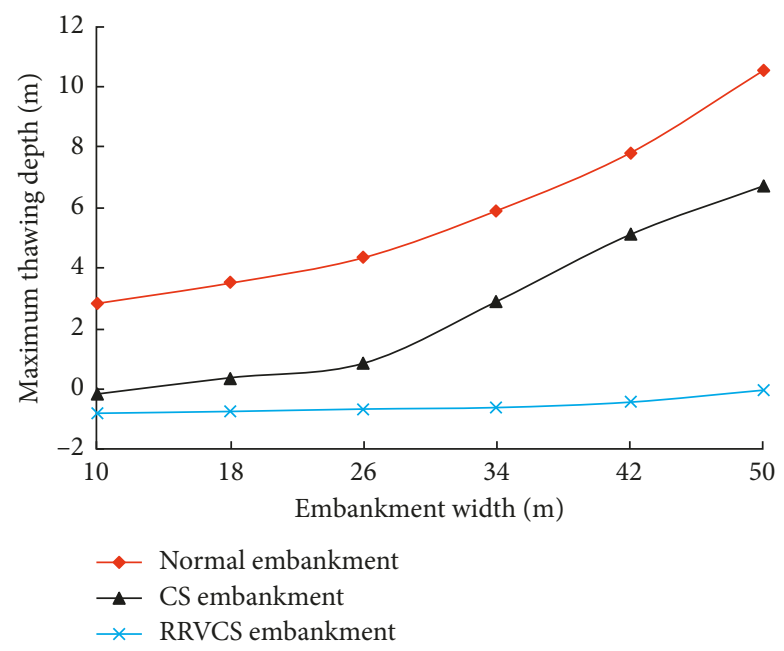

FIgURE 13: The maximum thawing depth versus embankment width for different embankments.

\section{Results and Discussion}

4.1. Influences of RRVCS on the Temperature Field of Wide Embankment. Numerical analysis was conducted to obtain the thermal regimes of normal embankment without protective measures, embankment with crushed stone layer (CS embankment), and embankment with RRVCS (RRVCS embankment). Here, the width of all the embankments was chosen as $50 \mathrm{~m}$.

Figures 8 and 9 show the tenth-year temperature fields of the three different embankments in January and August, respectively (the temperature decreases gradually when the color changes from red to blue). From Figure 8, it can be seen that, even at the coldest season, obvious thawing core (represented by the dark red zone with temperature higher than $0^{\circ} \mathrm{C}$ ) was found within the normal embankment and the CS embankment. However, the thawing core within the normal embankment is much larger than that within the CS embankment. Meanwhile, there is no thawing core within the RRVCS embankment.

From Figure 9, it can be seen that the $0^{\circ} \mathrm{C}$ contour of the CS embankment is closer to the natural ground surface than that of the normal embankment. While the $0^{\circ} \mathrm{C}$ contours (shown as the edge of the blue zone with temperature lower than $0^{\circ} \mathrm{C}$ ) of normal embankment and CS embankment are beneath the natural ground, the $0^{\circ} \mathrm{C}$ contour of RRVCS embankment is above the natural ground (within the embankment). It proves that both crushed stone layer and RRVCS can improve the thermal regime of wide embankment; however, RRVCS embankment has better improving effects. 
4.2. Influences of RRVCS on the Temperature Variations of Wide Embankment. Figure 10 shows the temperature variations during two decades at the $5 \mathrm{~m}$ depth of centerline for different embankments. It can be seen from Figure 10 that all of the three embankments present similar trends: the temperature varies periodically over time but the annual average temperature keeps increasing. The temperature of normal embankment exceeds $0^{\circ} \mathrm{C}$ after the 10 th year, which indicates that the thawing depth of normal embankment has been larger than $5 \mathrm{~m}$ since the 10th year. However, the temperature of CS embankment and RRVCS embankment is all less than $0^{\circ} \mathrm{C}$ during the two decades; hence, their thawing depths are less than $5 \mathrm{~m}$. At the same time point, normal embankment has the highest temperature while RRVCS embankment has the lowest temperature. As a result, RRVCS embankment can slow down the degradation trend of permafrost and has the best thermal stability compared with the other two types of wide embankments.

\subsection{Influences of RRVCS on the Thawing Depth of Wide} Embankment. The temperature variations with depth at the centerline for different embankments are shown in Figure 11. It shows that the temperatures decrease with the depth increasing and $0^{\circ} \mathrm{C}$ appears at smaller depth for embankment with protective measures. Meanwhile, at the same depth of underlying permafrost, embankment with RRVCS has lowest temperature, which indicates that RRVCS embankment has the least disturbance on the underlying permafrost.

Figure 12 shows the variations of maximum thawing depth with service time for embankments with different widths. It is clearly indicated that, for the same embankment width and service time, the RRVCS embankment has the smallest thawing depth while the normal embankment has the biggest thawing depth. The thawing depth of CS embankment is smaller than that of normal embankment but larger than that of RRVCS embankment. The maximum thawing depth twenty years after embankment construction versus embankment width is shown in Figure 13. It can be seen that with the increase of the embankment width, the thawing depth of normal embankment keeps increasing rapidly while the thawing depth of RRVCS embankment increases slowly. For CS embankment, the thawing depth increases slowly with the embankment width increasing when the embankment width is less than $26 \mathrm{~m}$ but increases rapidly with the embankment width increasing after the embankment width exceeds $26 \mathrm{~m}$. Therefore, the cooling effects of crushed stone layer can be obviously weakened by wide embankment with width exceeding $26 \mathrm{~m}$. Meanwhile, the thawing depth differences between normal embankment and RRVCS embankment increase continuously with embankment width increasing. Thus, the RRVCS embankment has the best protective effects for the thermal regime of the wide embankment section.

\section{Conclusions}

(1) Vermiculite powder has great influences on the thermal property of asphalt mixture. The thermal conductivity can be reduced by $22.8 \%, 29.5 \%, 37.3 \%$, and $50.6 \%$ after the addition of $4 \%, 6 \%, 8 \%$, and $10 \%$ vermiculite powder.

(2) The temperatures of normal embankment and embankments with protective measures all change periodically over time, but the mean temperatures rise. At the same time, the temperatures of RRVCS embankment are much lower and the time to reach the maximum temperature is obviously delayed compared with the other embankments.

(3) Both crushed stone layer and RRVCS can improve the thermal regime of wide embankment. However, after the width of embankment exceeds $26 \mathrm{~m}$, the protective effects of crushed stone layer are obviously weakened by increasing embankment width. Since the reflective coating and heat-resistant pavement are to provide heat resistance for permafrost ground in hot reason and crushed stone layer aims to facilitate the heat dissipation of permafrost ground during cold season, the RRVCS has the best protective effect for wide embankment.

(4) The reflective-resistant-ventilated coupling structure proposed in this paper provides a promising way to protect the wide embankment of expressway in permafrost zones. It is proposed to be used in the construction of the Qinghai-Tibet Expressway.

\section{Data Availability}

All of the data supporting the conclusions of the study are available in the article and the authors are willing to share the data underlying the findings of the article.

\section{Conflicts of Interest}

The authors declare that there are no conflicts of interest regarding the publication of this paper.

\section{Acknowledgments}

This study was financially supported by the Open Fund of State Engineering Laboratory of Highway Maintenance Technology (Changsha University of Science \& Technology, kfj160104), Natural Science Foundation of Jiangsu (BK20161421), National Natural Science Foundation of 363 China (no. 51378006), and Fundamental Research Funds for the Central Universities (no. 2242015R30027).

\section{References}

[1] T. Wang, G. Q. Zhou, X. Jiang, and J. Z. Wang, "Assessment for the spatial variation characteristics of uncertain thermal parameters for warm frozen soil," Applied Thermal Engineering, vol. 134, pp. 484-489, 2018.

[2] C. Yuan, Q. Yu, Y. You, and L. Guo, "Formation mechanism of longitudinal cracks in expressway embankments with inclined thermosyphons in warm and ice-rich permafrost regions," Applied Thermal Engineering, vol. 133, pp. 21-32, 2018. 
[3] S. J. Wang, J. B. Chen, J. Z. Zhang, and Z. L. Li, "Development of highway constructing technology in the permafrost region on the Qinghai-Tibet plateau," Science in China Series E: Technological Sciences, vol. 52, no. 2, pp. 497-506, 2009.

[4] H. J. Jin, Q. H. Yu, S. L. Wang, and L. Z. Lü, "Changes in permafrost environments along the Qinghai-Tibet engineering corridor induced by anthropogenic activities and climate warming," Cold Regions Science and Technology, vol. 53, no. 3, pp. 317-333, 2008.

[5] Y. Sheng, J. M. Zhang, Y. Z. Liu, and J. M. Wu, "Thermal regime in the embankment of Qinghai-Tibetan highway in permafrost regions," Cold Regions Science and Technology, vol. 35 , no. 1 , pp. 35-44, 2002.

[6] G. D. Cheng, "A roadbed cooling approach for the construction of Qinghai-Tibet railway," Cold Regions Science and Technology, vol. 42, no. 2, pp. 169-176, 2005.

[7] R. Fortier, A. M. Leblanc, and W. B. Yu, "Impacts of permafrost degradation on a road embankment at Umiujaq in Nunavik (Quebec), Canada," Canadian Geotechnical Journal, vol. 48, no. 5, pp. 720-740, 2011.

[8] Q. B. Wu and F. J. Niu, "Permafrost changes and engineering stability in Qinghai-Xizang plateau," Chinese Science Bulletin, vol. 58, no. 10, pp. 1079-1094, 2013.

[9] Q. B. Wu and T. J. Zhang, "Changes in active layer thickness over the Qinghai-Tibetan plateau from 1995 to 2007," Journal of Geophysical Research, vol. 115, no. 9, pp. 1-12, 2010.

[10] Q. H. Yu, Y. Z. Liu, and C. J. Tong, "Analysis of the subgrade deformation of the Qinghai-Tibetan highway," Journal of Glaciology and Geocryology, vol. 24, no. 5, pp. 623-627, 2002.

[11] C. Zhang, H. N. Wang, Z. P. You, and B. Ma, "Sensitivity analysis of longitudinal cracking on asphalt pavement using MEPDG in permafrost region," Journal of Traffic and Transportation Engineering (English Edition), vol. 2, no. 1, pp. 40-47, 2015.

[12] Q. H. Yu, X. C. Pan, G. D. Cheng, and Y. Bai, "Heat transfer process of roadway embankments with different type and width of road surface in permafrost regions," Progress in Natural Science, vol. 17, no. 3, pp. 314-319, 2007.

[13] J. P. Li and Y. Sheng, "Analysis of the thermal stability of an embankment under different pavement types in high temperature permafrost regions," Cold Regions Science and Technology, vol. 54, no. 2, pp. 120-123, 2008.

[14] Z. Wen, S. Yu, W Ma, and J. L. Qi, "In situ experimental study on thermal protection effects of the insulation method on warm permafrost," Cold Regions Science and Technology, vol. 53, no. 3, pp. 369-381, 2008.

[15] J. J. Wu, W. Ma, Z. Z. Sun, and Z Wen, "In-situ study on cooling effect of the two-phase closed thermosyphon and insulation combinational embankment of the Qinghai-Tibet," Cold Regions Science and Technology, vol. 60, no. 3, pp. 234-244, 2010.

[16] B. X. Sun, L. J. Yang, Q. Liu, W. Wang, and X. Z. Xu, "Experimental study on cooling enhancement of crushed rock layer with perforated ventilation pipe under airtight top surface," Cold Regions Science and Technology, vol. 68, no. 3, pp. 150-161, 2011.

[17] J. W. Zhang, J. P. Li, and X. J. Quan, "Thermal stability analysis under embankment with asphalt pavement and cement pavement in permafrost regions," Scientific World Journal, vol. 2013, Article ID 549623, no. 12, pp. 1-12, 2013.

[18] G. D. Cheng, Y. M. Lai, Z. Z. Sun, and F. Jiang, "The 'thermal semi-conductor' effect of crushed rocks," Permafrost and Periglacial Processes, vol. 18, no. 2, pp. 151-160, 2007.
[19] Y. F. Du, Q. Shi, and S. Y. Wang, "Highly oriented heatinduced structure of asphalt pavement for reducing pavement temperature," Energy and Buildings, vol. 85, pp. 23-31, 2014.

[20] JTG F40-2004, Technical Specifications for Construction of Highway Asphalt Pavement, China Communications Press, Beijing, China, 2004.

[21] J. Qian, Q. H. Yu, Y. H. You, J. Hu, and L. Guo, "Analysis on the convection cooling process of crushed-rock embankment of high-grade highway in permafrost regions," Cold Regions Science and Technology, vol. 78, pp. 115-121, 2012.

[22] B. X. Sun, X. Z. Xu, Y. M. Lai, S. J. Wang, and J. Z. Zhang, "Impact of ballast grain sizes on natural convection cooling effect of embankment in permafrost regions," Chinese Journal of Geotechnical Engineering, vol. 26, no. 6, pp. 809-814, 2004.

[23] R. L. Harlan, "Analysis of coupled heat-fluid transport in partially frozen soil," Journal of Water Resource Research, vol. 9, no. 5, pp. 1314-1323, 1973.

[24] S. J. Wang, "Study on highway subgrade stabilization and prediction technique in plateau permafrost region," Ph.D. thesis, Southeast University, Nanjing, China, 2005.

[25] S. J. Wang, X. M. Huang, and S. G. Hou, "Numerical analyses of pavement deformation and stress in permafrost regions," Journal of Glaciology and Geocryology, vol. 28, no. 2, pp. 217-222, 2006. 


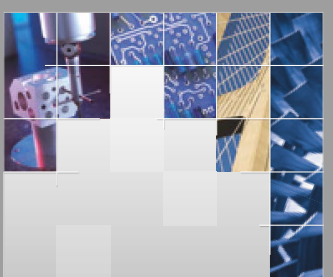

\section{Enfincering}
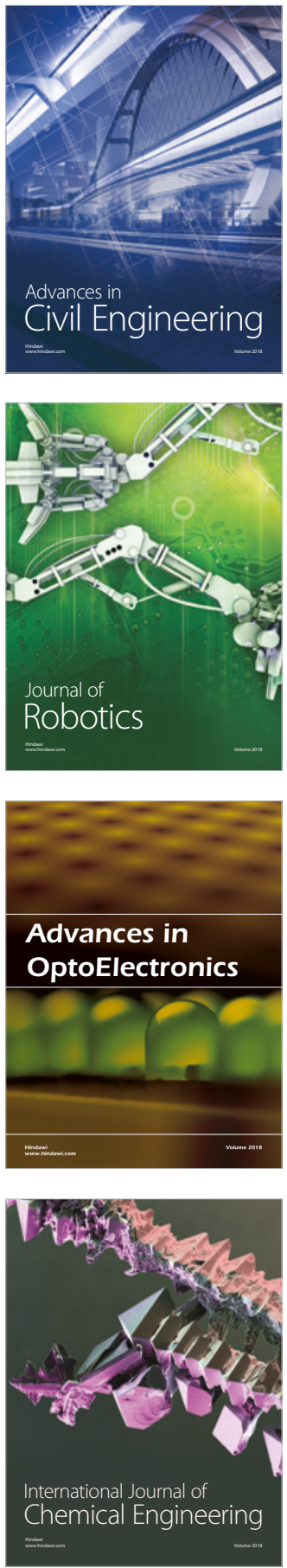

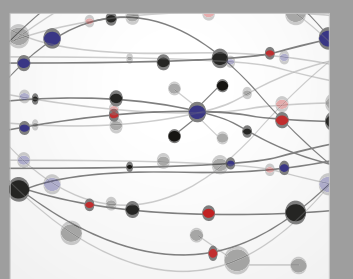

\section{Rotating \\ Machinery}

The Scientific World Journal

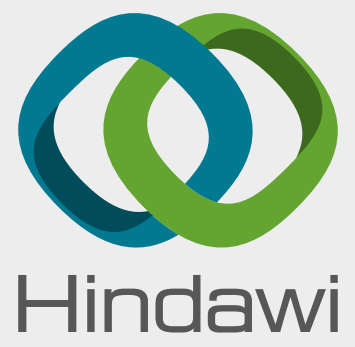

Submit your manuscripts at

www.hindawi.com
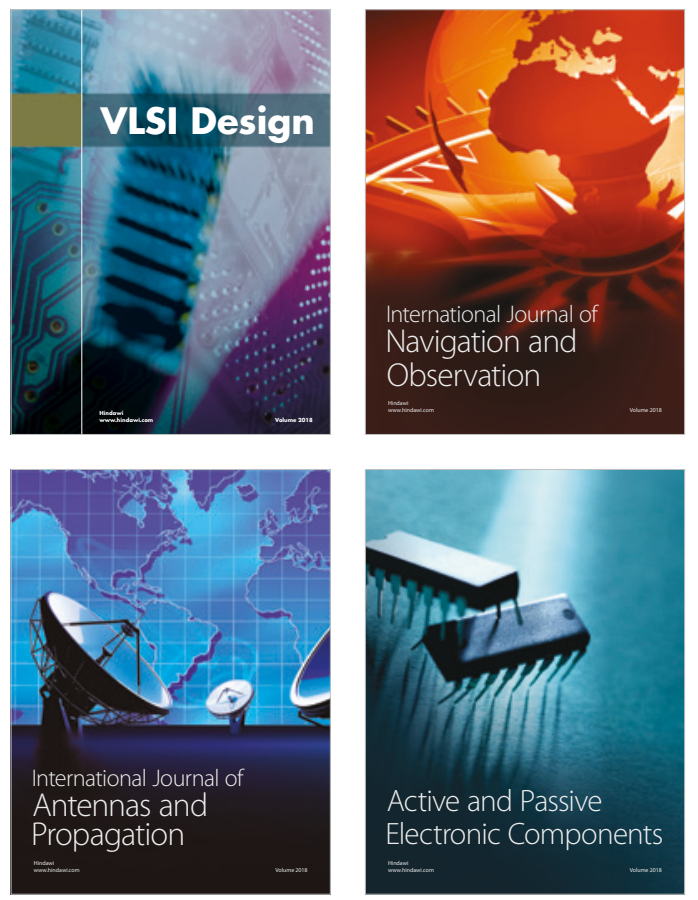
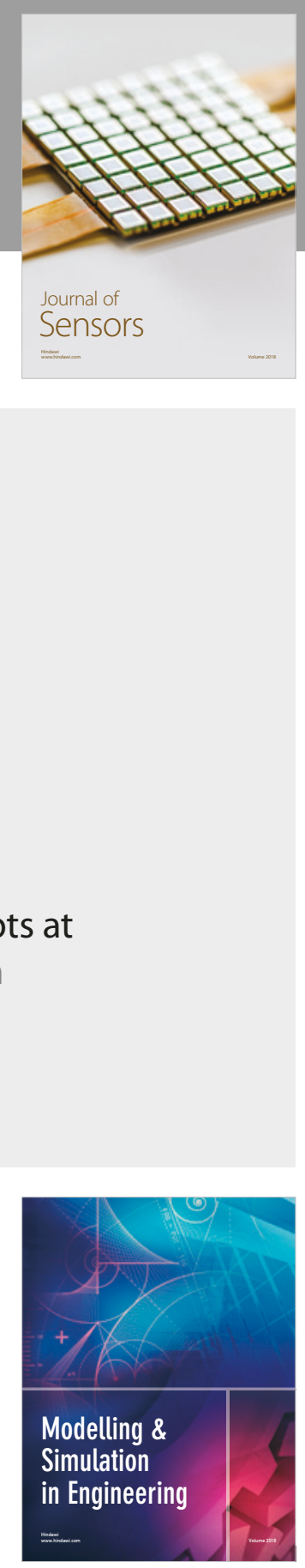

\section{Advances \\ Multimedia}
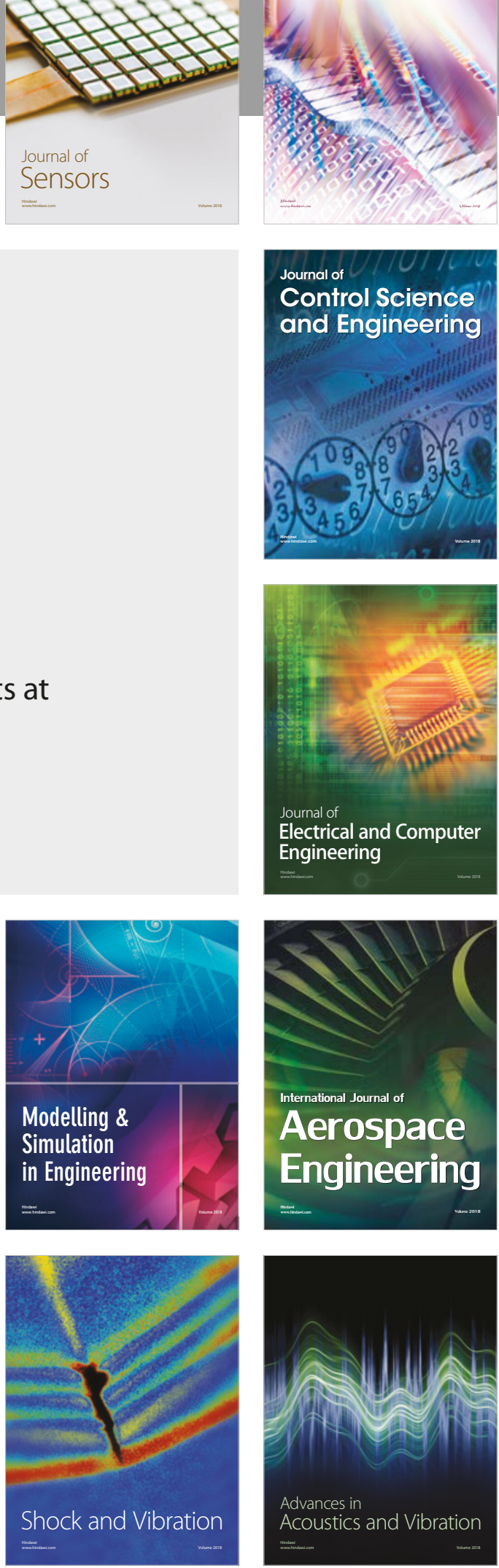